\title{
High-temperature three-colour thermal imager
}

\begin{abstract}
The influence of uncertainty of emissivity on the true temperature measurement errors is considered. Expressions for the optimal spectral range of thermal flux registration, that minimize an impact of uncertainty of emissivity, are obtained. Basic operation principles and parameters of high-temperature thermal imager based on 1/3-Inch Wide-VGA CMOS Digital Image Sensor MT9V034C12STC and notebook computer are described. In contrast to thermal imagers of Mikron 9103/9104 and PyroView series, thermal image registration is performed simultaneously in three overlapping regions of near-infrared spectrum. This allows to perform the emissivity evaluation and to reduce the error in determining the temperature that arises from the uncertainty of thermal emissivity coefficient.

Streszczenie. W artykule omówiono wpływ niepewności wartości współczynnika promieniowania cieplnego $\varepsilon$ na błąd pomiaru rzeczywistej temperatury. Sformułowano wzory pozwalające na wybór zakresu widmowego optymalnego do rejestracji strumieni cieplnych, które minimalizują wpływ niepewności $\varepsilon$. Opisano podstawowe zasady działania i parametry wysokotemperaturowej kamery termowizyjnej na bazie 1/3-Inch Wide-VGA CMOS Digital Image Sensor MT9V034C12STC i laptopa. W przeciwieństwie do wysokotemperaturowych kamer termowizyjnych serii Mikron 9103/9104 i PyroView rejestracja obrazu termicznego jest przeprowadzana jednocześnie w trzech nakładających się częściach widma bliskiej podczerwieni, co pozwala oszacować $\varepsilon$ i zmniejszyć błąd wyznaczenia temperatury wynikający z niepewności współczynnika promieniowania cieplnego (Wysokotemperaturowa trójkolorowa kamera termowizyjna).
\end{abstract}

Key words: imaging pyrometers, non-contact high temperature measurements, three-colour thermal imager.

Słowa kluczowe: pirometry obrazujące, bezdotykowe pomiary wysokotemperaturowe, trójkolorowa kamera termowizyjna.

\section{Introduction}

To ensure the quality of products made by the mechanical engineering enterprises, the mandatory use of devices for continuous temperature measurements of metals being hardened, forged, hammered, etc. is required (Fig. 1) [1]. Typically, the temperature is measured by partial radiation pyrometers or spectral ratio pyrometers. To determine the true temperature $T$, one needs to consider the effective thermal emissivity $\varepsilon_{e f}$ of the surface under test or the ratio of thermal emissivities $\varepsilon_{e f 1} / \varepsilon_{e f 2}$ in the pyrometer ( $\varepsilon_{e f 1}$ and $\varepsilon_{e f 2}$ are the emissivities in the given spectral regions, relatively) $[2,3]$. In the production environment the accurate determination of $\varepsilon_{\mathrm{ef}}$ is impossible because it depends on many factors $[4,5]$. Furthermore, in machinebuilding enterprises usually the range of manufactured products is wide and the number of the produced sets is small. In order to assure the production quality the application of new generation pyrometric equipment which can not only detect and visualize the temperature fields but also is invariant to the unsteadiness and the heterogeneity of the thermal radiation coefficient is required (Fig. 1-2).

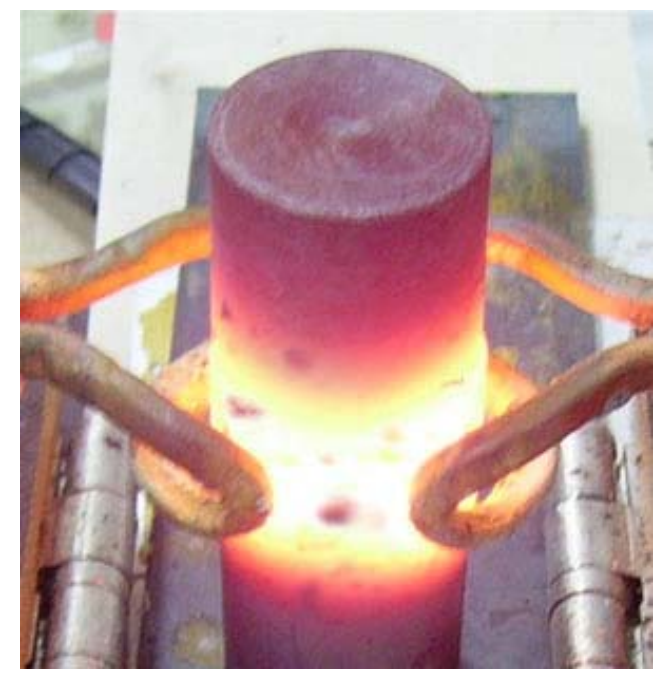

Fig. 1. Induction heating of the steel preform: distribution of temperature and thermal radiation brightness on the surface is uneven; heat scale spots are seen on the surface
Commercially available partial radiation pyrometers or spectral ratio pyrometers determine only the temperature value averaged over the field of view and are not adapted to operate in the above mentioned difficult conditions.

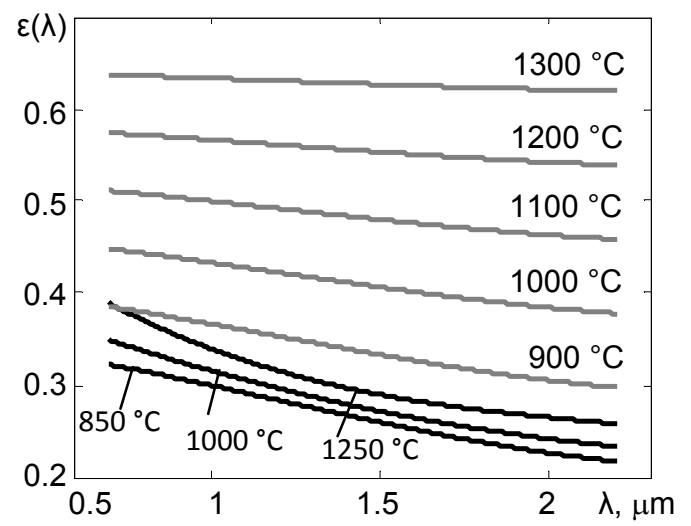

Fig. 2. Approximate changes in steel thermal emissivity during heating (black curves) and gradual oxidation (gray curves)

Application of thermal imaging technique which detects the thermal radiation in the range of 8-14 microns for adjustment and control of high-temperature thermal processes of metal processing is limited by a strong dependence of the metal thermal emissivity in the midinfrared spectrum range on the surface state. In this spectral range the metal emissivity is low and varies greatly during the oxidation by atmospheric oxygen during storage and heating, that leads to high uncertainty for $\varepsilon$ value (Fig. 2). For measuring the metal temperature in the range exceeding $800^{\circ} \mathrm{C}$ it is preferable to apply pyrometers which register the thermal radiation in the near-infrared region of the spectrum. In this region the emissivity is higher (Fig. 2), and a strong dependence of the spectral radiant emittance of a blackbody on the temperature (the Planck function $M(\lambda, T))$ is observed (Fig. 3).

In Mikron 9103/9104 thermal imagers [6] the monochrome matrix of $\mathrm{Si}$ photodetectors $(640 \times 480$ elements) and an optical filter with a maximum transmittance at a wavelength of about 0.8 micron are used to register the thermal radiation. In the case of known 
effective thermal emissivity $\varepsilon_{e f}$ and smoothing of image fluctuations by averaging of the image in time, it is possible to register the temperature field with a small systematic error (Fig. 4) [7]. At jump boundaries of the recorded temperature field the transient halos resulted from the partial filling of corresponding matrix pixels by image of a red-hot metal are observed.

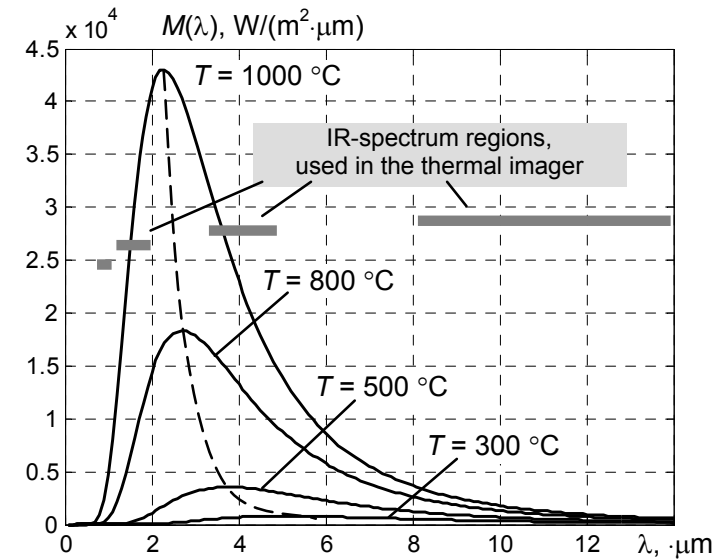

Fig. 3. The wavelength dependence of the spectral radiant emittance of blackbody at different temperatures

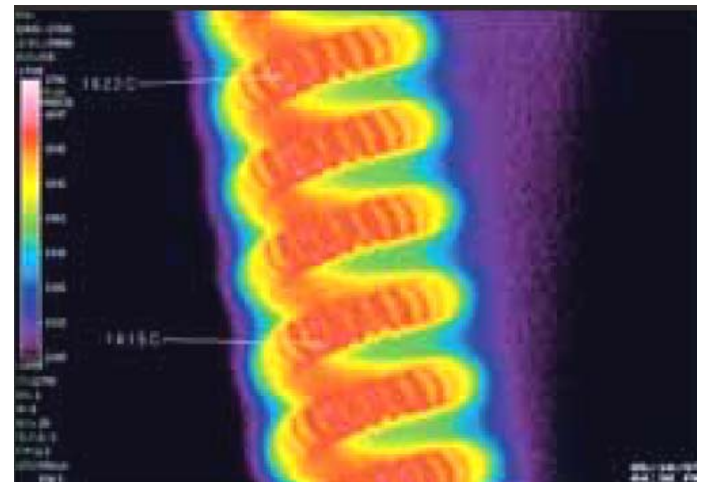

Fig. 4. Temperature field of red-hot lamp tungsten filament, obtained with the Mikron M9104 thermal imager

During heating the metal up to the high temperatures, $\varepsilon_{e f}$ quickly changes. Therefore the methods of recording and processing of thermal radiation fields which reduce the error of $\Delta T_{\varepsilon}$ determination caused by the uncertainty of $\varepsilon_{e f}$ should be used.

The relationship between the temperature measurement error and emissivity uncertainty

Using equation (1), that connects the true temperature $T$ and brightness temperature $T_{b}$ (using Planck's law),

$$
\frac{c_{1}}{\lambda^{5}}\left(e^{c_{2} /\left(\lambda T_{b}\right)}-1\right)^{-1}=\varepsilon \frac{c_{1}}{\lambda^{5}}\left(e^{c_{2} /(\lambda T)}-1\right)^{-1},
$$

where: $c_{1}$ and $c_{2}$ are the first and second radiation constants, respectively; $\lambda$ is the wavelength, at which the thermal radiation is measured,

the following dependence of the true temperature $T$ on $\varepsilon$ and $T_{b}$ can be obtained:

$$
T=\frac{c_{2}}{\lambda} \frac{1}{\ln \left[1+\varepsilon\left(e^{c_{2} /\left(\lambda T_{b}\right)}-1\right)\right]} .
$$

The relationship between the temperature determination error and the uncertainty of $\varepsilon$ value is determined by the partial derivative:

$$
\frac{\partial T}{\partial \varepsilon}=\frac{c_{2}\left[e^{c_{2} /\left(\lambda T_{b}\right)}-1\right]}{\lambda} \frac{1}{\left\{\ln \left[1+\varepsilon\left(e^{c_{2} /\left(\lambda T_{b}\right)}-1\right)\right]\right\}^{2}} \frac{1}{1+\varepsilon\left(e^{c_{2} /\left(\lambda T_{b}\right)}-1\right)} .
$$

In cases when the reflected radiation of surrounding environment is small in comparison with intrinsic thermal radiation the analytical relationship between the relative error of temperature determination $\delta T_{\varepsilon}=\Delta T_{\varepsilon} / T$ and the relative error of $\varepsilon$ determination $\delta \varepsilon=\Delta \varepsilon / \varepsilon$ can be obtained. If we form the relationship between $\delta T_{\varepsilon}=|f(\lambda, T)| \delta \varepsilon$ and $\delta \varepsilon$, the following expression can be obtained:

$$
\delta T=\frac{\lambda T}{c_{2}}\left(1-e^{-c_{2} /(\lambda T)}\right) \delta \varepsilon .
$$

In order to minimize the error of temperature determination $\delta T_{\varepsilon}$ it is not enough to use only expression (3) because $\delta T_{\varepsilon} \rightarrow$ 0 at $\lambda \rightarrow 0$. The slope of the short wavelength tail of the Planck function (Fig. 3) increases with wavelength decreasing, and simultaneously spectral radiant emittance of the body decreases. When the body temperature decreases, it causes the weak thermal radiation and the increase in the contribution of photodetector unit noises and external backlighting of the surface under test into the temperature measurement error. Therefore, it is necessary to introduce an additional condition that the flux of intrinsic thermal radiation falling on the photodetector should be two orders of magnitude higher than those negative factors in order to reduce their contribution up to $1 \%$.

Illumination of the image of object field in the lens image forming plane is described by the following widely used expression:

$E_{\mathrm{u} 3}(\lambda, T)=\tau_{\mathrm{o}} \varepsilon(\lambda, T) M(\lambda, T) \frac{D^{2}}{4 f^{2}}\left(1-\frac{f}{Z}\right)^{2}=K \varepsilon(\lambda, T) M(\lambda, T)$,

where: $\tau_{0}, f$ and $D$ are the transmittance, focal length and diameter of the lens, relatively, $Z$ is the distance from the lens to the surface under test, $\varepsilon(\lambda, T)$ is the spectral emissivity of the surface in the direction of the observer; $K=\tau_{\mathrm{o}}\left(D^{2} / 4 f^{2}\right)(1-f / Z)^{2}$ is the coefficient that relates spectral emissivity of the surface and illumination of its image. If the condition $Z \geq 20 f$ is met, then the last multiplier $(1-f / Z)^{2}$ in $K$ is often neglected. Taking into account the area of the photosensitive layer of photodetector $S_{p d}$, one can obtain the nonlinear equation for determination of the wavelength at which the predetermined thermal radiation flux $\Phi_{t h}$ of the surface under test is ensured:

$$
K \varepsilon(\lambda, T) M(\lambda, T) S_{p d}-\Phi_{t h}=0 .
$$

Solving equation (4) numerically, one can get the temperature dependence of $\lambda_{\text {opt }}$ shown in Fig. 5 .

Using expressions (3) and (4), it is possible to plot a graph of temperature dependence of the relative error $\delta T_{\varepsilon}$ of the true temperature determination (Fig. 6) for the relative uncertainty in $\varepsilon$ value equal to 0.1 , and for the most common wavelengths used in the brightness pyrometer. Consideration of the threshold sensitivity of the photodetector unit allows one to determine the temperature dependence of the minimum values of $\delta T$ (dashed line in Fig.6), which can be achieved using the boundary wavelengths $\lambda_{N}(T)$ of thermal radiation registration (Fig.5) with the brightness pyrometer.

From the analysis of Fig. 5 it can be concluded that the temperature measurement of surfaces with non-stationary over time and nonuniform in surface behaviour of emissivity requires the correct choice of the wavelength of thermal radiation registration. The measuring of high temperatures by means of thermal imaging pyrometers of mid-infrared 
spectral range uncertainty of $\varepsilon$ value results in approximately eightfold increase in $\delta T_{\varepsilon}$ (because of uncertainty of $\varepsilon$ value) as compared to brightness pyrometers, which use radiation registration at the wavelength of $0.65 \mu \mathrm{m}$. In the cases of high relative uncertainty, for example $\delta_{\varepsilon}=1$ (for small $\varepsilon$ values), for midinfrared pyrometers the error $\delta T$ can be 0.7 , that is $70 \%$ of the measured value. For visible-range pyrometers this error does not exceed $10 \%$.

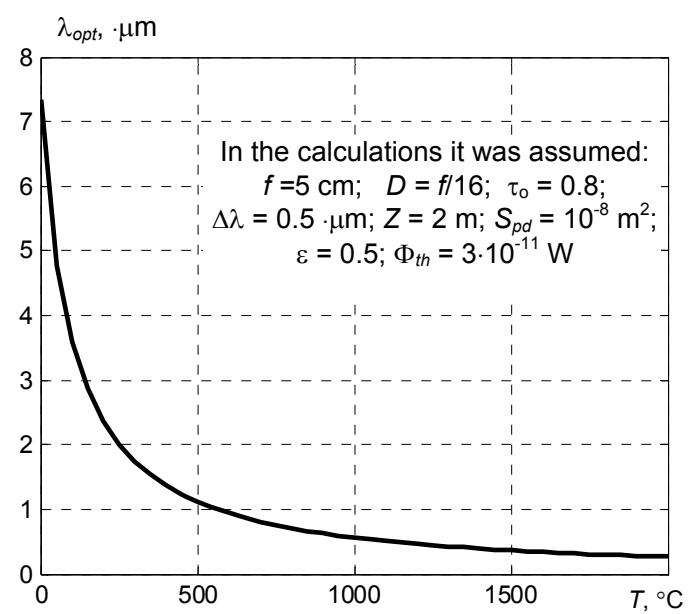

Fig. 5. Temperature dependence of $\lambda_{\text {opt }}$ at which the predetermined thermal radiation flux $\Phi_{t h}=3 \cdot 10^{-11} \mathrm{~W}$ falling on the photodetector from the surface under test is provided

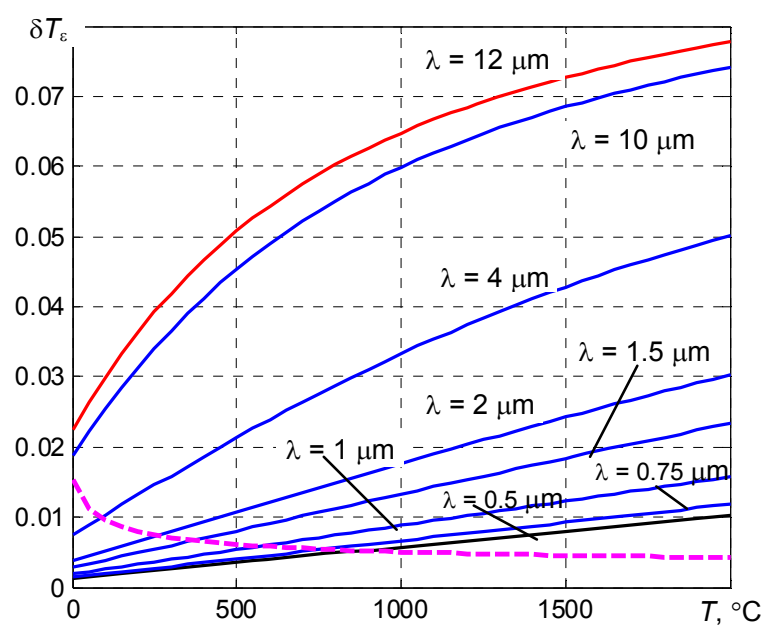

Fig 6. Temperature dependencies of $\delta T_{\varepsilon}$ for the relative uncertainty of $\varepsilon$ values equal to 0.1 and for the use of different wavelengths (solid lines); temperature dependence of $\delta T_{\varepsilon}$ for $\lambda_{\text {opt }}$ (dashed line)

In practice, pyrometers and thermal imagers of partial radiation which use the wide regions of spectrum in contrast to brightness pyrometers are widely applied. For these devices it is difficult to obtain analytical expressions similar to expressions (3) and (4). Therefore, we obtain the corresponding graph dependencies by the numerical methods. Integral illumination of the surface image can be calculated using the following expression:

$$
E(T)=K \int_{\lambda_{1}}^{\lambda_{2}} \tau_{f}(\lambda) \varepsilon(\lambda, T) M(\lambda, T) d \lambda,
$$

where: $\tau_{f}(\lambda)$ is transmittance of the optical filter installed in front of the photodetector. Assuming that $\tau_{f}(\lambda)=0.8$ in the filter passband and the conversion sleepness of the photodetector in this band can be considered to be constant, we obtain the following expression for calculating the integral flux falling to the light-sensitive area of the photodetector:

$$
\Phi(T)=K S_{p d} \int_{\lambda_{1}}^{\lambda_{2}} \tau_{\phi}(\lambda) \varepsilon(\lambda, T) M(\lambda, T) d \lambda .
$$

If put $\varepsilon(\lambda, T)=0.5$ and use the numerical differentiation of the expression (6) with respect to $\varepsilon$ for parameters given in Fig.5, we can obtain the temperature dependence of the relative error in true temperature determination (Fig. 7) for pyrometers and thermal imagers, which use the most common spectral regions of near-infrared spectral range [8, 9] and middle-infrared spectral range $[10,11]$ for the thermal radiation registration. Results obtained for the photodetector unit parameters indicated in Fig. 5 are shown in Fig. 7.

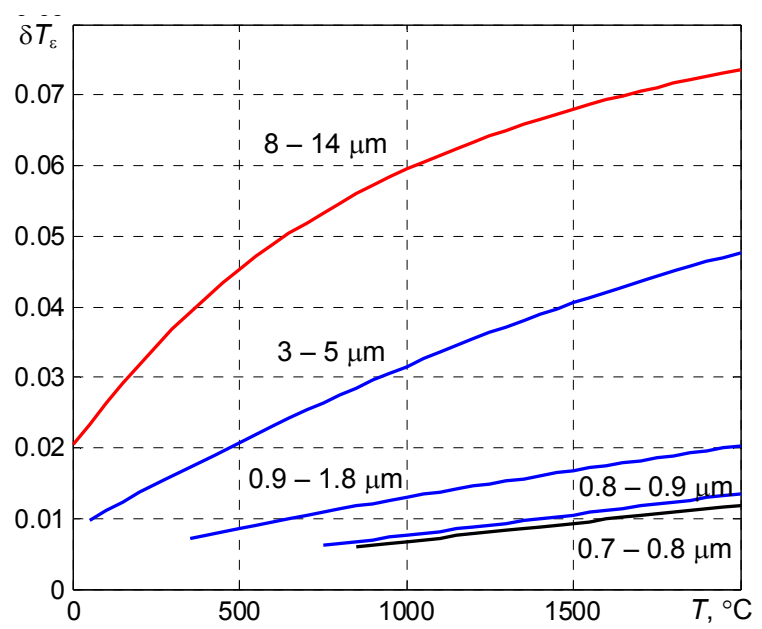

Fig. 7. Temperature dependencies of the relative errors of true temperature determination by the partial radiation thermal imagers using typical spectral bands for relative uncertainty of $\varepsilon$ value equal to 0.1

Comparing Fig. 6 with Fig. 7, it can be noted that the character of spectral dependence of the relative error of true temperature determination $\delta T_{\varepsilon}$ for the thermal imagers and pyrometers, which use the wide regions of spectrum, is about the same as for the devices for brightness temperature measurement.

The aforementioned graph dependencies indicate the need in matching the range of measured temperatures with the position of the spectrum region used to record the thermal radiation in the case of the significant uncertainty of $\varepsilon$.

In practice, for measuring the heated metal temperature, even when using optimal regions of the spectrum with respect to $\delta T_{\varepsilon}$ minimizing, the errors of the true temperature determination can exceed $10 \%$, that is unacceptable for setting-up the majority of thermal processes. In such cases, the algorithms of $T$ determination enable to reduce the $\delta T_{\varepsilon}$ value up to $2-3 \%$ are required.

\section{The ways to reduce the errors $\delta T_{\varepsilon}$}

During the development of pyrometry a considerable number of methods for determining the true temperature have been elaborated and patented [2, 3], but remained only as laboratory methods due to their complexity.

It should be noted that all methods for true temperature determination based on registration of radiant emittance of the surface under test will be related with the use of regularities of $\varepsilon(\lambda, T)$ behaviour. Analysis of the $\varepsilon(\lambda)$ dependencies obtained as a result of numerous experimental studies for various substances [4, 5] allows one to select the three most common dependencies for the near-infrared spectrum shown in Fig. 8, which are 
characteristic for dielectrics, "gray" bodies and metals. For metals, $\varepsilon$ value decreases with $\lambda$ increasing in the infrared region, that is, the slope coefficient $b=\Delta \varepsilon / \Delta \lambda$ is less than zero. For "gray" bodies $b=0$, and for dielectrics $b>0$.

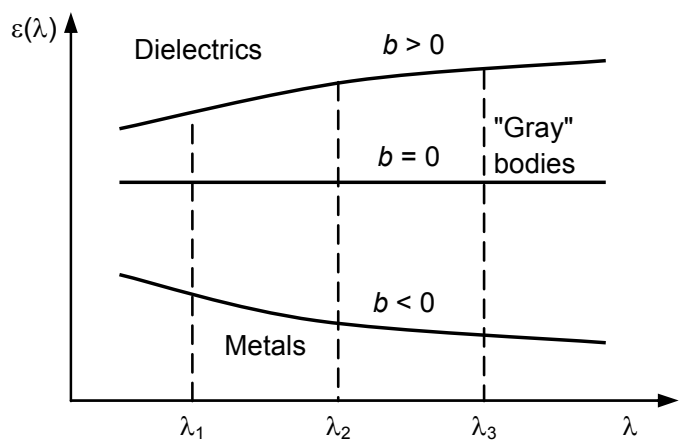

Fig. 8. The most common dependencies of the behaviour of spectral thermal emission coefficients in the near-infrared region of spectrum

The most convenient for practical use methods for $T$ determination are based on the simultaneous registration of thermal radiation in two or more spectral regions $[12,13]$.

One of the widely applied methods is a spectral ratio method based on the determination of the ratio of thermal radiation intensities in the two spectral regions. For "gray" body the true temperature $T$ coincides with the spectral ratio temperature $T_{s r}$. Therefore, about $15 \%$ of produced pyrometers are the spectral ratio pyrometers. The temperatures of metals measured by them are higher than true temperatures (Fig. 9). But usually deviation $\left|T_{s r}-T\right|$ is less than the difference $T$ - $T_{r}$, where $T_{r}$ is brightness temperature or partial radiation temperature if a wide spectral region is used.

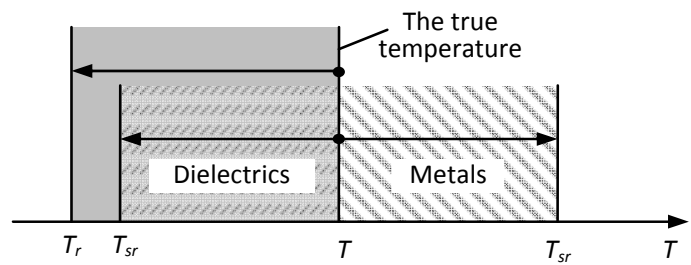

Fig. 9. Ranges of possible values of the partial radiation temperature $T_{r}$ and spectral ratio temperature $T_{s r}$

As can be seen from Fig. 8 , for $\varepsilon(\lambda) \neq$ const at least two parameters are required to describe the dependency $\varepsilon(\lambda)$. For example, $\varepsilon(\lambda)=\varepsilon_{2}+b\left(\lambda-\lambda_{2}\right)$ in the case of linear approximation or $\varepsilon(\lambda)=\varepsilon_{2} \cdot e^{b(\lambda-\lambda 2)}$ in the case of exponential approximation, where $\varepsilon_{2}$ is the coefficient of thermal radiation at a wavelength $\lambda_{2}$.

To form a system of nonlinear equations for the determination of the true temperature and two unknown parameters $\varepsilon_{2}$ and $b$, it is necessary to determine the intensity of thermal radiation in at least three regions of the spectrum $[14,15]$. Moreover, the distances $\left(\lambda_{2}-\lambda_{1}\right)$ and $\left(\lambda_{3}-\right.$ $\lambda_{2}$ ) between used regions of the spectrum should be selected on the basis of a compromise between two opposing factors. Increasing of these distances for improvement of the method sensitivity leads to the increase in the contribution of component, associated with the deviation of the real dependence $\varepsilon(\lambda)$ from the applied approximation [4], into the error $\delta T_{\varepsilon}[2,3]$. If $\left(\lambda_{2}-\lambda_{1}\right)$ and $\left(\lambda_{3}\right.$ $\left.-\lambda_{2}\right)$ are decreased, the method sensitivity decreases, and the contribution of photodetector unit noise, external backlighting and other noises into $\delta T$ increases.

It is probable that the underestimation of the influence of these factors causes the absence of successful implementation of three-colour pyrometers. Application of modern RGB matrices for the determination of the true temperature of metals $[16,17]$ is justified at temperatures higher than $1000{ }^{\circ} \mathrm{C}$. Moreover, the intrinsic thermal emission from the surface in the spectral region corresponding to the blue colour, should well exceed the reflected radiation light from lighting sources of industrial premises. If it is necessary to measure the temperature in the temperature range higher than $800{ }^{\circ} \mathrm{C}$ the spectral regions in the wavelength range higher than $600 \mathrm{~nm}$ should be used. In these regions, the dependence $\varepsilon(\lambda)$ can be roughly approximated by the exponential law.

Working principles and main features of the developed thermal imager

Wide-VGA CMOS Digital Image Sensor MT9V034C12STC is used in the developed thermal imager [18] to register the thermal image. Using an external light filter and considering the known dependencies of the quantum efficiency $\eta(\lambda)$ of RGB elements of this matrix (Fig. $10)$, it is possible to form three overlapping parts of the thermal radiation registration spectrum located in the red and near-infrared spectrum region. Spectral emissivity of ferrous metals $\varepsilon(\lambda)$ in this narrow spectral region can be approximated by the following exponential expression:

$$
\varepsilon(\lambda)=\varepsilon_{2} \exp \left[b\left(\lambda-\lambda_{2}\right)\right],
$$

where $\varepsilon_{2}$ is thermal emissivity in the middle of this region.

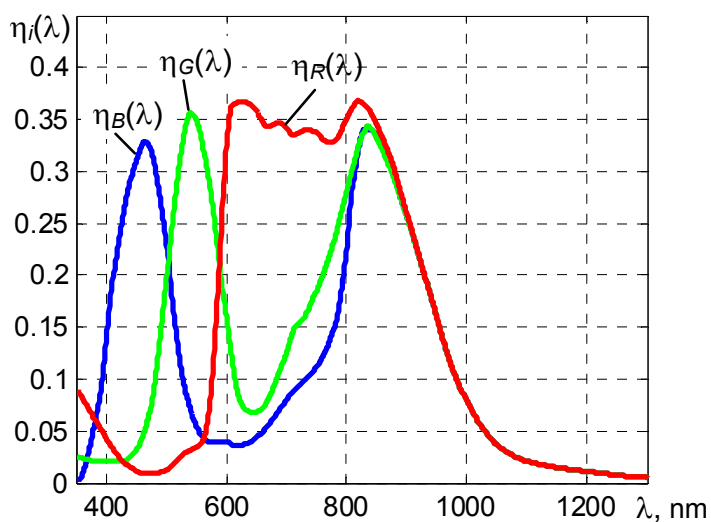

Fig. 10. Spectral quantum efficiencies of $R, G, B$ light-sensing elements of MT9V034STC matrix

Considering formula (7), $\eta_{i}(\lambda)$, and the parameters of the radiation heat flux registration scheme, and integrating the fluxes, falling on the R, G, B matrix elements, over $\lambda$ it is possible to obtain the expressions describing the dependence of the velocity $v=D / \tau$ of recorded digital signal $D$ rise on the true temperature of the red-hot metal surface:

$$
\left\{\begin{array}{l}
v_{1}=\varepsilon_{2}\left[1+b \mu_{1}(T)\right] F_{1}(T), \\
v_{2}=\varepsilon_{2}\left[1+b \mu_{2}(T)\right] F_{2}(T), \\
v_{3}=\varepsilon_{2}\left[1+b \mu_{3}(T)\right] F_{3}(T),
\end{array}\right.
$$

where $\tau$ is frame exposure time, $F_{i}(T)$ are calibration dependencies of $v_{i}$ values on the temperature of the absolute black body model (at $\varepsilon=1, b=0), \mu /(T)$ are dependencies of the contribution of the slop of $\varepsilon(\lambda)$ (that is value $b)$ into the signal rise velocities $v_{i}(T)$. Dependencies $\mu_{/}(T)$ have been calculated after the thermal imager calibration.

By solving the system of equations (8) the nonlinear equation can be obtained, the solution of which is the true temperature $T$ of the surface $[16,17]$. Unfortunately, due to 
the strong overlapping of the regions of thermal radiation registration formed in the range of $640-840 \mathrm{~nm}$, the distance between their effective wavelengths $\lambda_{1 \mathrm{ef}}, \lambda_{2 \mathrm{ef}}, \lambda_{3 \mathrm{ef}}$ is small, that requires high accuracy of $v_{i}$ determination. The relative error of $v_{i}$ determination should not exceed $10^{-4}$, which is unattainable in the case of using a thermal imager in a production environment. The widening of used spectral registration region leads to the increase in the contribution of deviation between practical and approximated (7) $\varepsilon(\lambda)$ dependencies. Therefore, it is necessary to use a priori information. For example, for the tungsten filament heated in inert gases, $\varepsilon_{2}$ can be excluded from system of equations (8), that allows to create the non-linear equations, the solution of which gives the true temperature with a small relative error $\delta T$ in spite of the change of the $\varepsilon_{2}$ value with temperature.

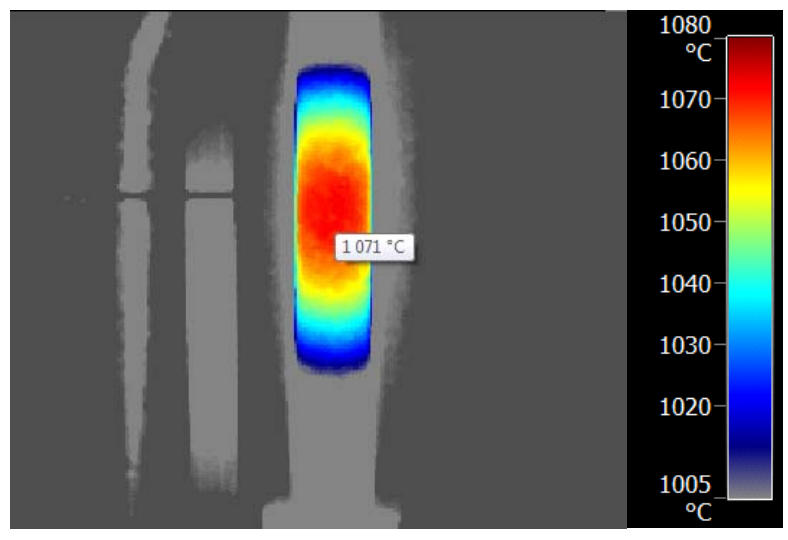

a
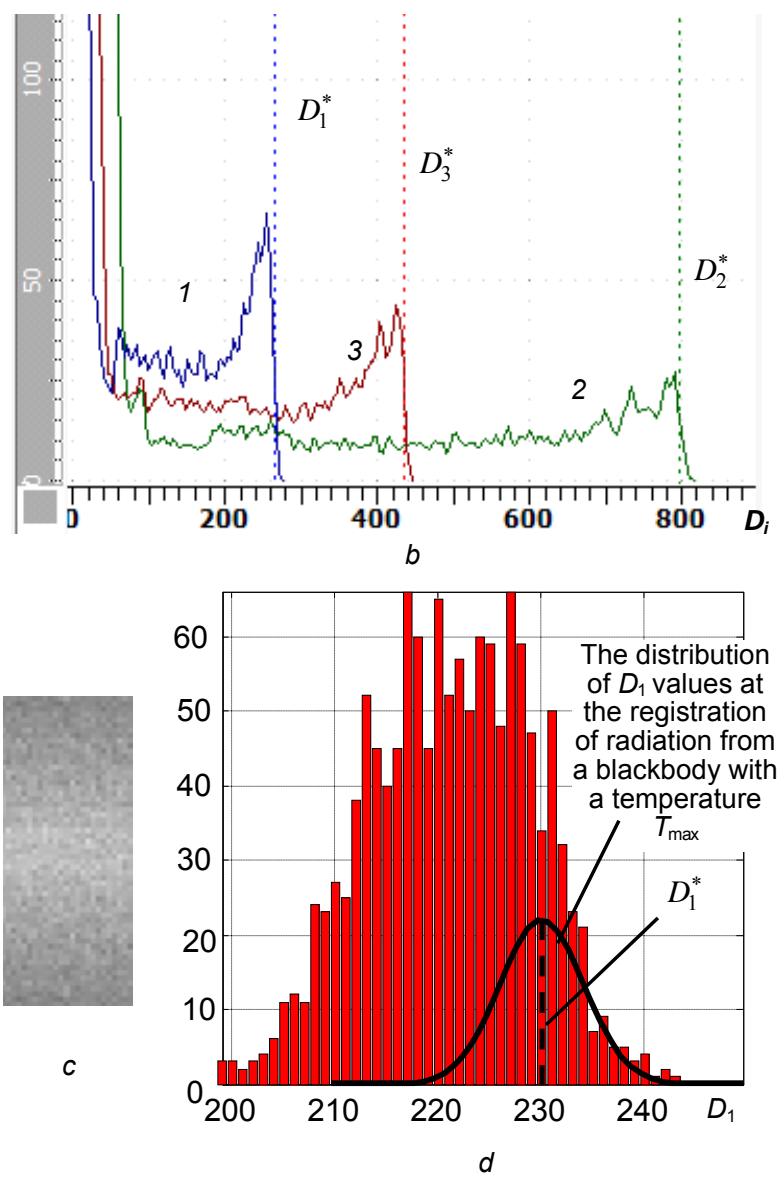

Fig. 11. Thermogram of non-uniformly heated tungsten stripe of lamp Ch10-300 (a), histograms of its digital thermal images in three spectral regions $(b)$, digital thermal image of the part of stripe $(c)$ and histogram of digital thermal image of the part of stripe $(d)$
For the metals that are usually oxidised when heated in an oxygen containing atmosphere, the $\varepsilon_{2}$ value increases (see Fig. 2) and, conversely, the $b$ value decreases approaching to zero at strong oxidation. This allows to find nonlinear equation for the determination of the true temperature with an acceptable error by the setting of the relationship between $\varepsilon_{2}$ and $b$; for example, $b=\varepsilon_{2} \gamma\left(1-\varepsilon_{2}\right)$, where $\gamma$ approximately equals to $-0.4 \mu \mathrm{m}^{-1}$ for ferrous metals.

Usually the largest brightness of thermal radiation is observed in the direction perpendicular to the radiating surface. Therefore, the main optical axis of the thermal imager lens at the calibration should be aligned with the normal to output aperture of the reference radiation source. Since the bodies under test have various shapes, the maximum temperature $T_{\max }$ over field of view should be displayed. This allows correct determining of the maximum temperature of small bodies, because the surface region with the normal directed to the imager lens will necessarily be in the thermal imager field of view. In the case of the spatial inhomogeneity of $\varepsilon$, e.g. uneven growing of the oxide film during heating, the areas with the minimal thickness of oxide film will be the brightest. The areas with thick oxide film due to its low thermal conductivity are strongly cooled by convection air fluxes and this leads to the appearing of dross spots (Fig. 1). Therefore, a special algorithm of determination of maximum temperature $T_{\max }$ based on the processing of histograms of the obtained thermal images [19] is applied in the thermal imager. The brightest regions are chosen and the averaging over their area is performed. The values of $D_{i}^{*}$ (Fig. 11) and $v_{i}^{*}=D_{i}^{*} / \tau$ are determined. Then the $v_{i}^{*}$ values are used for solving the system of equations in order to determine the maximum temperature $T_{\max }$ (Fig. 12) of the non-uniformly heated surface of the body.
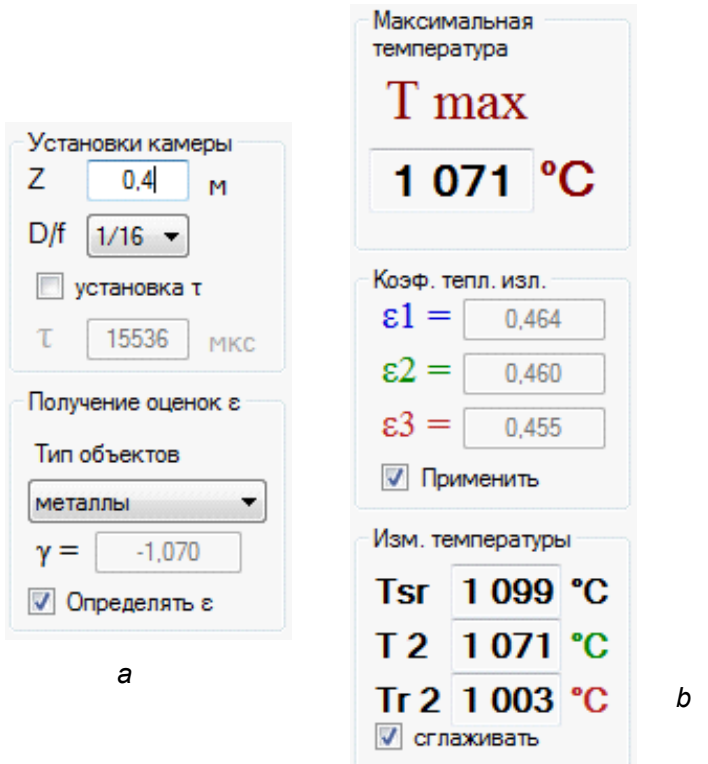

Fig. 12. Panels for setting the initial parameters (a) and measured values $(b)$ which were obtained for tungsten strip of lamp Ch10-300 (Fig. 11)

By using the option of $\varepsilon$ determination (Fig. 12a) and the obtained $v_{i}^{*}$ values the maximum values of the temperature spectral ratio $T_{s r}$, the true temperature $T$ and the partial radiation temperature $T_{r}$ are calculated. The values of these temperatures (Fig. 12) obtained for non-uniformly heated strip of lamp СИ10-300 (Fig. 11) correspond to their positions in Fig. 9. 
During hardening process monitoring the cooling liquid vapour can get into the field of view of the thermal imager. To reduce an impact of vapour on the measured temperature values, the option of time averaging of the obtained temperature values by a sliding window with a maximum length of 36 readings, based on the linear regression method is provided. Application of the regression methods for smoothing the temperature is due to the linear dependence of the heated body temperature on time at a constant heating power. Registered thermal radiation fluxes increase nonlinearly, so their smoothing is less effective.

The design, basic parameters and examples of the application of the thermal imager

Development of single-block thermal imager is expensive. Therefore, the thermal imager comprises a digital video unit and a processing unit based on a laptop or tablet, which are interconnected with a USB cable [18]. Usage of a laptop for the processing of 10-bit video flux data, for the temperature field formation, recording of a controlled heat engineering process, data storage and reproduction considerably reduces the cost of the thermal imager's development and extends its functionality. For easy installation and mounting of the video unit, the tripod or magnetic suction cup with the mechanism of the precise viewing of the controlled area is used (Fig. 13).

In addition to the measurement mode, the program controlling the operation of the thermal imager provides the calibration mode, in which the temperatures of used blackbody model are entered from the keyboard and calibration tables are automatically generated. This program also calculates the polynomial coefficients required for the calculation of the three partial radiation temperatures $T_{r i}$ and the spectral ratio temperature.

The panels for entering the distance to the controlled surface, the lens parameters, and exposure time $\tau$ (if the control of pulse processes is needed) are provided. The necessary buttons for control of thermal imager operation, recording of controlled processes and their reproduction are generated by software. When viewing the records it is possible to change the parameters used in the temperature field calculation and frame-by-frame displaying. In the measurement mode one can choose the type of temperature output values, as well as the option of automatic determination of the $\varepsilon_{e f 1}, \varepsilon_{e f 2}$, $\varepsilon_{e f 3}$ values, and the value of true temperature $T_{\max }$, by setting the flags (Fig. 12). When forming the temperature field of the image with resolution of $376 \times 240$ pixels, both the vertical colour temperature scale and the Jet palette with all rainbow colours are applied.

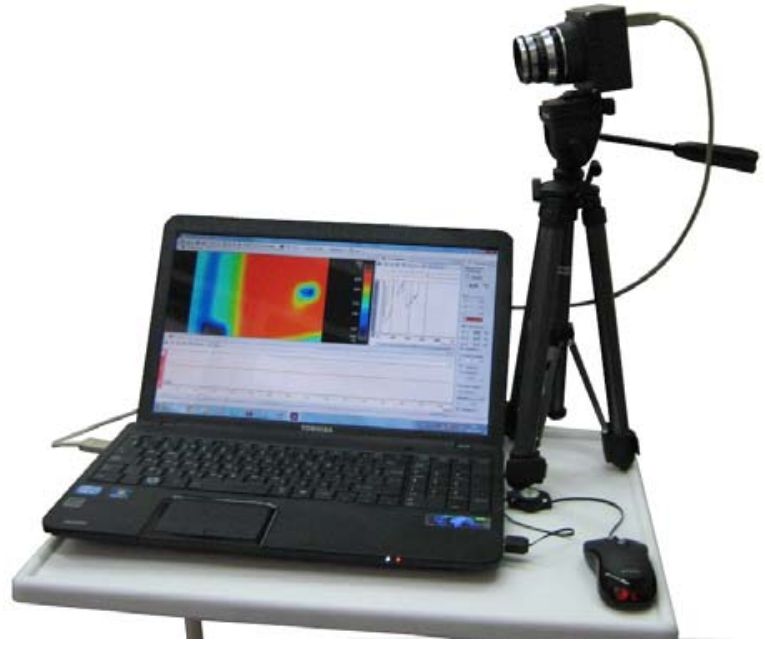

Fig. 13. High-temperature three-color thermal imager
The frequency of frame getting and processing depends on the used exposure time $\tau$, and for exposure time less than $30 \mathrm{~ms}$ the frequency exceeds $30 \mathrm{~Hz}$. Possibility of manual adjustment of the frame getting frequency is provided.

The basic parameters of the developed hightemperature thermal imager [18] are shown in Table. 1.

Table 1. Basic parameters of the thermal imager

\begin{tabular}{|l|l|}
\hline \multicolumn{1}{|c|}{ Parameter } & \multicolumn{1}{|c|}{ Value } \\
\hline $\begin{array}{l}\text { Measured temperature range, } \\
{ }^{\circ} \mathrm{C}\end{array}$ & From +800 to +1700 \\
\hline $\begin{array}{l}\text { Acceptable absolute error of } \\
\text { reference radiation source } \\
\text { temperature measurement, }{ }^{\circ} \mathrm{C}\end{array}$ & \pm 5 \\
\hline Photodetector type & $\begin{array}{l}\text { VGA photodetector } \\
\text { matrix MT9V034STC }\end{array}$ \\
\hline Number of RGB elements & $752 \times 480$ \\
\hline $\begin{array}{l}\text { Spectral range of registered } \\
\text { thermal radiation, } \mu \mathrm{m}\end{array}$ & $0,63-0,83$ \\
\hline $\begin{array}{l}\text { Angle of field of view } \\
\text { Frequency of frames, Hz }\end{array}$ & $\begin{array}{l}\text { Is determined by the } \\
\text { parameters of lens used }\end{array}$ \\
\hline $\begin{array}{l}\text { Time of displaying the } \\
\text { determined temperature, s }\end{array}$ & not less than 0.5 \\
\hline $\begin{array}{l}\text { Option of regression smoothing } \\
\text { of measured temperature } \\
\text { values }\end{array}$ & Available \\
\hline $\begin{array}{l}\text { Option of approximate } \\
\text { estimation of the effective } \\
\text { emissivity of the body }\end{array}$ & Available \\
\hline
\end{tabular}

The examples of thermograms of thermal technical processes, which were recorded by the developed thermal imager, are shown in Figs. 14 and 15. From these Figures it can be seen that there is the influence of the inhomogeneity of coefficient of thermal radiation and the external backlight on the obtained partial radiation temperature $T_{r}(\mathrm{x}, \mathrm{y})$.

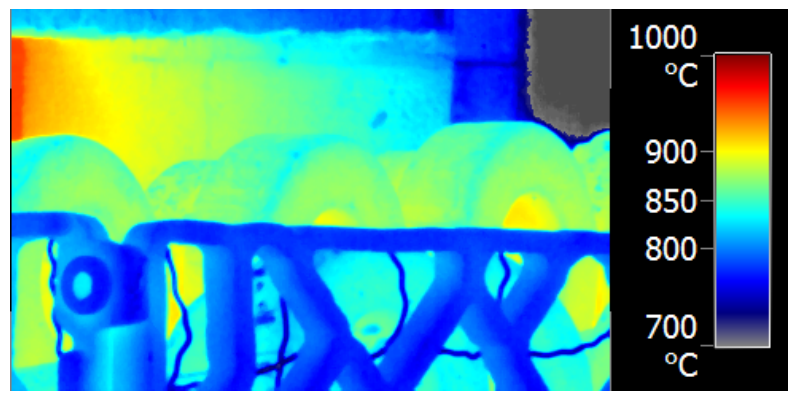

Fig. 14. Thermogram $T_{r}(\mathrm{x}, \mathrm{y})$ of blanks discharged from the furnace for subsequent quenching

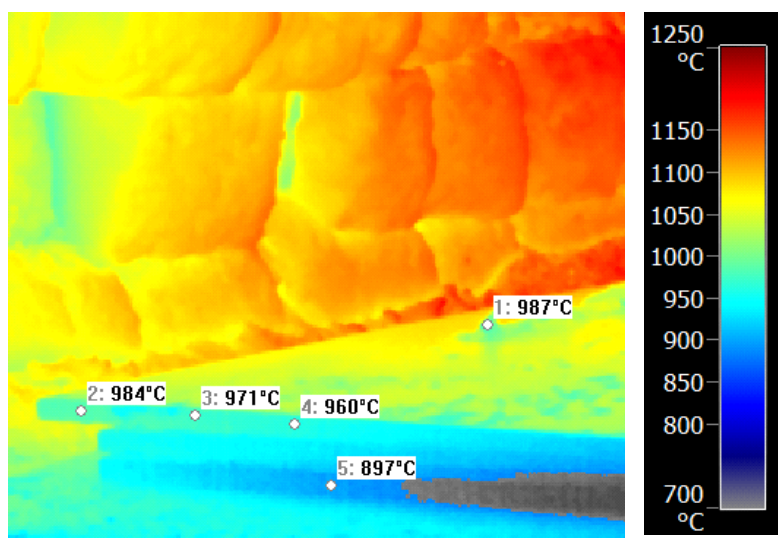

Fig. 15. Thermogram $T_{r}(\mathrm{x}, \mathrm{y})$ of three metal sheets heated in a gas furnace registered with the open door 
The thermogram of blanks discharged from the furnace (Fig. 14) has a considerable variations of $T_{r}$ from 850 to $900{ }^{\circ} \mathrm{C}$. In fact, the surface temperatures of the blanks are identical because the basket with blanks pulled out from the furnace $3 \mathrm{~s}$ before the image was obtained. Emissivity of weakly oxidized surfaces of the blanks is approximately 0.6 Therefore, generally $T_{r} \approx 850-870{ }^{\circ} \mathrm{C}$. The cylindrical cavities of these blanks radiate like black bodies, i.e. their emissivity $\varepsilon \approx$ 0.9 . Therefore, the true temperature of the blanks is close to $900^{\circ} \mathrm{C}$.

Thermal radiation from the hot furnace walls reflected from the upper metal sheet (Fig. 15) considerably distorts the temperature $T_{1}(x, y)$, up to $100^{\circ} \mathrm{C}$. However, in the areas, where there is an oxide film with $\varepsilon \approx 0.8-0.9$ (spots with smaller values of $T_{r}$ ), the reflected radiation is weak. Temperature $T_{r}$ measured at these points (e.g., point 1 in Fig. 15), is close to the temperature of left edge of the top sheet (point 2). Right ends of the edges of the metal sheets were cooled by power air convective flux appeared when furnace door was opened.

\section{Summary}

Registration of thermal radiation in three sections of the spectrum, use of the described technical solutions, lack of rotating parts, simple structure, use of commercially onecrystal Wide-VGA CMOS Digital Image Sensor MT9V034C12STC and a standard notebook computer can significantly extend the functionality of high-temperature thermal imager and reduce the cost of its production. The use of proposed exponential approximation of the spectral thermal emissivity and three regions for thermal flux registration enables the evaluation of $\varepsilon$ value. In this case, the relative error of true temperature $\delta T_{\varepsilon}$ determination of ferrous metals is reduced to the values of $0.015-0.02$, suitable in practical applications. Conventional thermal imagers that use one region of the spectrum ensure the higher errors $\delta T_{\varepsilon}(0.08-0.12)$ for the uncertainty of $\varepsilon$ value.

\section{REFERENCES}

1] www.electricalschool.info/main/drugoe/235-indukcionnyii-nagrevi-indukcionnaja.html

[2] Snopko V.N. Basics of pyrometry methods on the the thermal radiation spectrum. Minsk, 1999 [In Russian]

[3] Svet D. Ya. Optical methods of the true temperature measurement. Moscow, 1982. [In Russian]

[4] Radiative properties of solid materials: reference book./ Editor A.E. Sheidlin. . Moscow, 1974. [In Russian]
[5] Burakowski T., Giziński J., Sala A. Podczerwień i jej zastosowanie Wyd. MON, Warszawa 1963.

[6] www.IRimaging.com

[7] A Unique Ultra High Resolution Thermal Imager I Mikron Infrared Inc. Thermal Imaging Division.

[8] United States Patent № 4, 687,344 B1, G01J 5/02 Imaging Pyrometer, Date of Patent 18.08.1987.

[9] www.new-imaging-technologies.com/ingaas-products.html. WDR InGaAs Product Range.

[10]

www.dias-infrared.com/products/infraredcameras/infraredcameraspyroviewcompact. Infrared cameras PYROVIEW compact -universal and compact

[11] www.flir.com

[12] Firago V., Sen'kov A., Wojcik W., Chorba Y. Pyrometric methods of measuring the true temperature of heated metals. New Electrical and Electronic Technologies and their Industrial Implementation NEET 2011. Zakopane, Poland, June 28 - Jule 1, 2011, p. 116

[13] Sen'kov A., Firago V. Errors in Measuring the Temperature of Metals by Pyrometers Based on Tricolor Multielement Photodetectors. Journal of Engineering Physics and Thermophysics, vol. 81/No. 6, 2008, p. 1046-1057

[14] Firago V., Volkova I.: Pyrometric methods of the true temperature determination at the thermal radiation registration in three spectral regions / VIII Int. Conference «New Electrical and Electronic Technologies and their Industrial Implantation» Zakopane, Poland, June 18-21, 2013. P. 139.

[15] Firago V., Wojcik W., Dzhunisbekov M., Volkova I. High temperature thermal imager based on digital video camera mvBlueFOX 200wc / VIII Int. Conference «New Electrical and Electronic Technologies and their Industrial Implantation» Zakopane, Poland, June 18-21, 2013. P. 141.

[16] Republic of Belarus Patent 14292, G01J 5/00 Pyrometric method of determining the thermodynamic temperature of the body, Date of Patent 2009.06.04 - 8 p. [In Russian]

[17] Sen'kov A.G., Firago V.A. Three-color pyrometric method of determining the temperature of hot metal // Electronics Info. 2009. - № 5. - p. 50 - 54. [In Russian]

[18] www.unitehprom.by

[19] Republic of Belarus Patent 13991, G01J 5/00 Method for determining the maximum temperature of the unevenly heated metal surface, Date of Patent 2009.03.13 - 5 p. [In Russian]

Authors: dr Vladimir Firago, Department of Quantum Radiophysics and Optoelectronics, Belarusian State University, Nezaliezhnasti Av. 4, 220030 Minsk, E-mail: firago@bsu.by; prof. dr hab. inż. Waldemar Wójcik, Institute of Electronics and Information Technologies, Lublin University of Technology, Nadbystrzycka Str., 38D, 20-618 Lublin, E-mail: waldemar.wojcik@pollub.pl 